\title{
Measurement, evaluation, and assessment of occupational exposures to hand-transmitted vibration
}

M J Griffin

Abstract

The measurement of hand-transmitted vibration converts oscillatory movements to a form in which they can be evaluated with respect to human responses and assessed for their acceptability. This paper presents methods of measurement, evaluation, and assessment currently advocated in standards and other forms of guidance. The degree to which the methods of evaluating different frequencies, directions, and durations of vibration affect the assessment of vibration on different tools is illustrated. With the frequency weighting currently used to allow for the effects of different frequencies there is little need to measure vibration at frequencies as high as $1000 \mathrm{~Hz}$; this has significant implications to the design and evaluation of proposed antivibration devices, including gloves. Without the current frequency weighting, vibration at frequencies greater than $250 \mathrm{~Hz}$ can contribute to the magnitude of the vibration, but many common causes of injury from hand-transmitted vibration have their dominant components of vibration below $250 \mathrm{~Hz}$. On many powered tools, although the dominant frequency of vibration is the same before and after frequency weighting, the reported magnitude of vibration is greatly affected by the frequency weighting. On tools with dominant low frequencies, their vibration is rated as being of far greater importance relative to other tools when considering frequency-weighted acceleration than when considering unweighted acceleration. It is shown that the effect of considering three axes of vibration as opposed to one axis has a greater effect on some tools than on others. The uncertainties and assumptions involved in the measurement, evaluation, and assessment of hand-transmitted vibration are reviewed. It is suggested that whereas current decisions on health and welfare should be based on current assessment methods, the measurement and evaluation of hand-transmitted vibration should involve the collection and reporting of data which allow other interpretations in the future.

(Occup Environ Med 1997;54:73-89)

Keywords: vibration; dose-effect relations; vibrationinduced white finger; standards
Throughout history, mechanical impacts associated with accidents and aggression have caused acute injuries to the human body. During the past century, it has been observed that repeated impacts (vibration and repeated shock) with sufficiently low magnitudes so that they do not individually cause detectable injury, can give rise to signs and symptoms of chronic disorders. The cause-effect relation between impacts and acute injury is self evident, although not always easily predicted. The cause-effect relation between vibration and chronic disorders has been more opaque: the elapse of time between cause and effect and the complexity of both the cause and the effect have helped to conceal their relation.

In the United Kingdom, one of the first published reports of vibration-induced injuries appeared in the 1907 report of the Departmental Committee on Compensation for Industrial Diseases. ${ }^{1}$ Paragraph 33 of the report states:

“33. Neurosis due to Vibration-Our attention was called to neurosis due to vibration, caused by the use of pneumatic tools. Tremor and sleeplessness have occasionally been observed in individuals, but no evidence was obtained of the existence of any nervous disease from this cause which incapacitates from employment."

The committee did not recommend that vibration-induced disorders should be added to the schedule of diseases in the Workmen's Compensation Act. Compensation required that a disease or injury caused incapacitation from work for a period of more than one week, and that the disease or injury was so specific to the employment that the causation from employment could be established in individual cases. Deafness, acknowledged to be widely prevalent among boilermakers in the shipyards, was not accepted for compensation as it did not prevent a man from continuing at his trade. Early published reports of people affected by hand-transmitted vibration were also published in Italy and the United States. ${ }^{2-5}$

Compensation for vibration-induced injuries to the hand was reconsidered several times in the United Kingdom over the next 80 years, but did not come into force until 1 April 1985 when compensation was restricted to "episodic blanching, occurring throughout the year, affecting the middle or proximal phalanges ... on one hand ... any three of those fingers" among people in a specified set of 
Table 1 Five types of disorder associated with handtransmitted vibration exposures ${ }^{8}$

\begin{tabular}{ll}
\hline Type & Disorder \\
\hline A & Circulatory \\
B & Bone and joint \\
C & Neurological \\
D & Muscle \\
E & Other general (for example, central nervous system)
\end{tabular}

Some combinations of these disorders are sometimes referred to as hand-arm vibration syndrome (HAVS).

occupations. ${ }^{6}$ More recently, recognition that hand-transmitted vibration from various tools may cause disorders as well as finger blanching (table 1) led to a recommendation that the scope of the compensation should be extended to include neurological effects. ${ }^{7}$ In other countries, there are various patterns of compensation for vascular, neurological, and articular disorders thought to be associated with handtransmitted vibration.

What type of vibration causes injury? The provision of an answer is impeded by the complexity of the problem and the need to use jargon associated with science, engineering, and medicine. Knowing that vibration causes injury leads to attempts to represent the vibration by means of numbers (measurement). Vibration can be measured without knowledge of the effects it produces. To discern the relative or absolute severity of the vibration (evaluation), or to identify the likely consequences of exposure to the vibration (assessment), it is necessary to have knowledge of the cause-effect relation between vibration and injury.

MEASUREMENT, EVALUATION, AND ASSESSMENT The measurement of vibration requires that the oscillatory movements are transduced (the energy is converted to a form representing the movements). The method of measurement has changed over the years according to the availability of transducers having appropriate sensitivity, size, cost, etc. In the past 50 years the most commonly used types of transducers have been accelerometers which, by one means or another, convert the acceleration of the surface to which they are attached into an electrical signal. No transducer has the capability to fully represent all possible motions: the measured signal is a sufficient representation of the vibration when it follows the relevant parts of the motion (the frequencies, magnitudes, and directions of interest) with appropriate accuracy. This involves assumptions as to which parts of the motion cause the disorders of interest. Measurements can be stored for later consideration as tables of numbers, as waveforms drawn on paper, as analogue recordings on magnetic tape, or in a digitised form for use by computers.

The evaluation of measurements of human response requires the use of procedures which show the relative or absolute severity of the vibration: it may not be appropriate to assume that all frequencies or all directions of motion are of equal importance. An evaluation procedure will result in one (or a few) numbers so that the severities of different vibration exposures can be compared. This requires knowl- edge of the relative importance of different qualities in the measurement (frequencies, directions, durations). The evaluation may be expressed by values on either an interval or a ratio scale (a scale on which differences between intervals on the scale have some quantitative significance). Similar to the frequency weightings used in acoustics, it has become common practice to "weight" vibration with a weighting reflecting the assumed effects of different vibration frequencies, directions, and durations. It is then possible to report a single weighted value which is assumed to be representative of the severity of the complex motion which was measured.

The assessment involves a consideration of the vibration and a judgement about it. Whereas the evaluation results in a numerical value representative of the vibration severity, the assessment predicts the outcome of a vibration exposure: the type, severity, or probability of disorder, or even the legal consequences. An assessment does not necessarily require measurement and evaluation of vibration: a particular type or source of vibration exposure could be labelled as unacceptable and banned without knowledge of the vibration magnitudes.

The boundaries between measurement, evaluation, and assessment are easily and, too often, blurred. The ability to make an assessment without measurement and evaluation allows the possibility of making this judgement and merely resorting to physical values to support the conclusion. This happens with individual assessments and also in the process of standardisation, when the measurement and evaluation methods may be selected to reach the desired conclusion rather than being justified in their own right. The separate identification of a measurement method, an evaluation procedure, and an assessment criterion may encourage a more rigorous route to both individual assessments and the production of standards containing guidance.

The objective of this paper is to present the current method of measuring the severity of exposures to hand-transmitted vibration and show the consequences of this method. This requires an initial consideration of the physical variables influencing vibration severity, before summarising the method advocated in current national and international standards. The consequences of assumptions implicit in the standards are shown and the implications for the future course of standards are considered.

Physical variables and their measurement Table 2 shows some of the principal physical

Table 2 Physical variables relevant to the effects of handtransmitted vibration

Magnitude of vibration

Frequency of vibration

Direction of vibratio

Duration of vibration

Area of contact with vibration

Contact force (grip force and push force)

Finger, hand, and arm posture

Environment (for example, temperature) 
variables influencing the severity of handtransmitted vibration.

\section{VIBRATION MAGNITUDE}

A vibrating object moves to and fro over some displacement with alternately a velocity in one direction and then a velocity in the opposite direction. The change of velocity means that the object is constantly accelerating, firstly in one direction and then in the opposite direction. The magnitude of a vibration can be measured by either its displacement, its velocity, or its acceleration. For practical convenience, the magnitude of vibration is now usually expressed in terms of the acceleration and is measured with accelerometers. The units of acceleration are $\mathrm{ms}^{-2}$. Magnitudes of hand-transmitted vibration are currently expressed as an average measure of the acceleration of the oscillatory motion: the rootmean-square value $\left(\mathrm{ms}^{-2} \mathrm{rms}\right)$.

\section{VIBRATION FREQUENCY}

Vibration frequency is expressed in cycles per second using the SI unit, hertz $(\mathrm{Hz})$. The frequency of vibration influences both the manner and the extent to which vibration is transmitted through hand-held machinery, the extent to which it is transmitted through the fingers, hand, and arm, and the responses to the vibration within the body. The relation between the displacement and the acceleration of an oscillatory motion is also dependent on the frequency of oscillation: a peak to peak displacement of only $1 \mathrm{~mm}$ corresponds to a low acceleration at low frequencies (for example, about $0.9 \mathrm{~ms}^{-2} \mathrm{rms}$ at $8 \mathrm{~Hz}$ ) but increasing acceleration at increasing frequencies-for example, $140 \mathrm{~ms}^{-2} \mathrm{rms}$ at $100 \mathrm{~Hz}$, and 14000 $\mathrm{ms}^{-2} \mathrm{rms}$ at $1000 \mathrm{~Hz}$. The vibration displacement, which can be seen with the eye, does

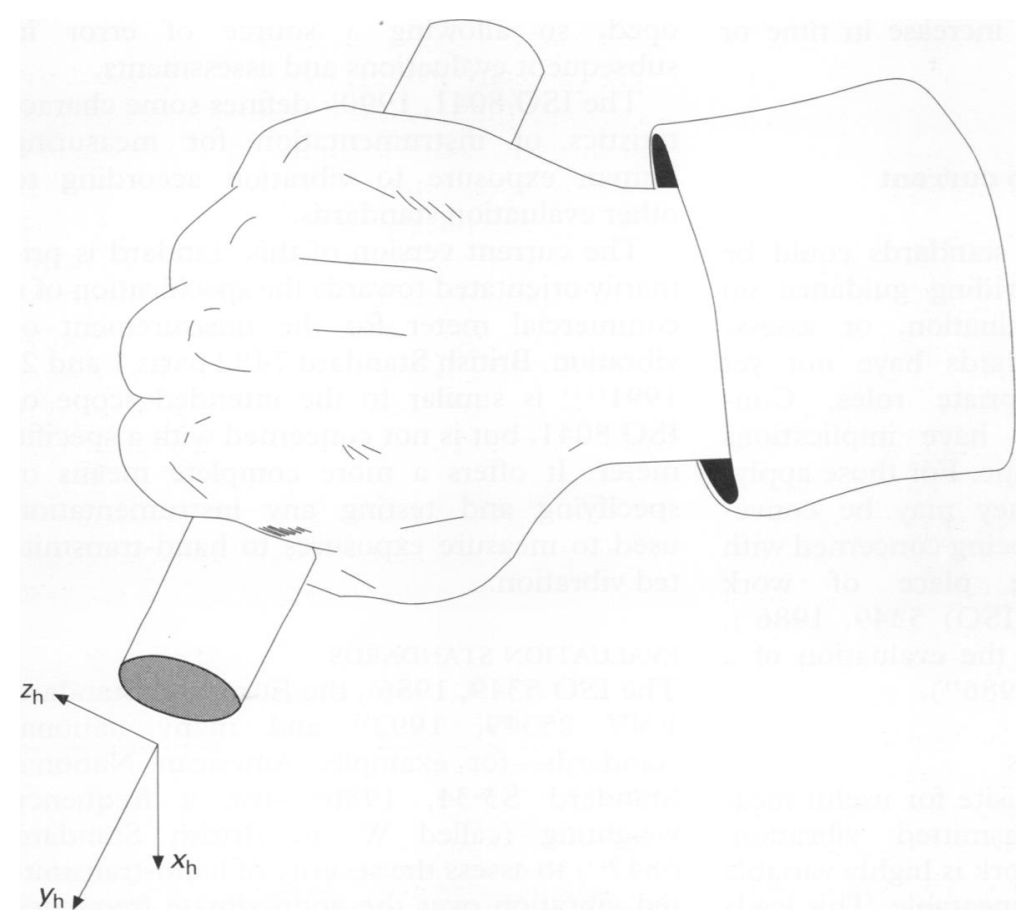

Figure 1 Axes of vibration used to measure exposures to hand-transmitted vibration. not give an indication of the acceleration magnitude.

\section{VIBRATION DIRECTION}

The transmission of vibration into the hand differs according to the direction of the applied vibration. The effects of vibration within the hand and arm may also depend on the axis of vibration. Vibration is measured on the handle of a tool close to the hand in three orthogonal directions designated $x, y$, and $z$ (fig 1). The axes may be defined relative to the orientation of the hand or relative to the tool. The position and orientation of a hand on a tool may vary. In consequence it is often more convenient to quote the vibration magnitudes relative to three convenient axes of the tool rather than the axes of the hand.

\section{VIBRATION DURATION}

Some human responses to vibration depend on the duration of exposure. Also, the duration of measurement may affect the measured magnitude of the vibration. The measurement of vibration with rms averaging assumes a time dependency in which doubling the magnitude of a transient acceleration is equivalent to a fourfold increase in the duration of the event. The rms acceleration may not provide a good indication of vibration severity if the vibration is intermittent, contains shocks, or otherwise varies in magnitude from time to time. ${ }^{8}$

\section{OTHER VARIABLES}

Although other variables (the area of contact with vibration, the grip force, and posture) probably influence the severity of vibration exposures, there are currently no standardised methods of measuring them.

\section{MEASUREMENT METHODS}

One or more accelerometers with the capability to both withstand and indicate the vibration to which they are exposed are secured to a surface adjacent to the hand..$^{910}$ The mounting method should be rigid at frequencies up to and above $1000 \mathrm{~Hz}$. On tools that cause shocks, mechanical filters between accelerometers and the tool may be used to attenuate the very high frequency acceleration which causes some transducers to give erroneous readings at low frequencies (dc shifts ${ }^{8}$ ). The total mass of accelerometer and mount must be sufficiently low so as not to influence the vibration on the tool. Few reported measurements on tools have identified the adequacy of the mounting method or shown that the mass of the mount has no effect on measurements. Future standards may identify the requirements with more precision and give guidance on how they can be achieved.

The evaluation of vibration may be achieved by analogue or digital methods, by dedicated instruments or by general purpose equipment. Dedicated instruments which only provide an indication of the frequencyweighted acceleration may seem to be convenient but have drawbacks: the absence of spectral information prevents the observation of spectra as a "signature" of the vibration giv- 
Table 3 Some tools and processes potentially associated with vibration injuries

\begin{tabular}{|c|c|}
\hline Type of tool & Examples of tool type (standards identifying type test) \\
\hline Percussive metal-working tools & $\begin{array}{l}\text { Riveting tools (ISO 8662-2) } \\
\text { Caulking tools (ISO 8662-5) } \\
\text { Chipping hammers (ISO 8662-2) } \\
\text { Clinching and flanging tools (ISO 8662-10) } \\
\text { Impact wrenches (ISO 8662-7) } \\
\text { Impact screw drivers (ISO 8662-7) } \\
\text { Nut runners (ISO 8662-7) } \\
\text { Scaling hammers (ISO 8662-10) } \\
\text { Needle guns (ISO 8662-10) } \\
\text { Nibbling machines and shears ((ISO 8662-10) } \\
\text { Swaging }\end{array}$ \\
\hline Grinders and other rotary tools & $\begin{array}{l}\text { Pedestal grinders } \\
\text { hand-held grinders (ISO 8662-4; ISO 8662-8) } \\
\text { hand-held sanders ((ISO 8662-4; ISO 8662-8) } \\
\text { hand-held polishers (ISO 8662-4) } \\
\text { Flex driven grinders or polishers ((ISO 8662-17) } \\
\text { Rotary burring tools (ISO 8662-17) } \\
\text { Files (ISO 8662-12) }\end{array}$ \\
\hline $\begin{array}{l}\text { Percussive hammers and drills } \\
\text { used in mining, demolition, road } \\
\text { construction, and stone working }\end{array}$ & $\begin{array}{l}\text { Hammer drills (ISO } 8662-3 \text { ) } \\
\text { Rock drills (ISO 8662-3) } \\
\text { Tampers and rammers (ISO 8662-9) } \\
\text { Road breakers (ISO 8662-5) } \\
\text { Stone working tools (ISO 8662-14) }\end{array}$ \\
\hline Forest and garden machinery & $\begin{array}{l}\text { Chain saws (ISO 7505) } \\
\text { Antivibration chain saws (ISO 7505) } \\
\text { Brush saws } \\
\text { Mowers (ISO 5395) } \\
\text { Hedge cutters and trimmers } \\
\text { Barking machines } \\
\text { Stump grinders }\end{array}$ \\
\hline Other processes and tools & $\begin{array}{l}\text { Nailing gun (ISO 8662-11) } \\
\text { Stapling gun (ISO 8662-11) } \\
\text { Pad saws (ISO 8662-12) } \\
\text { Circular saws (ISO 8662-12) } \\
\text { Scabblers } \\
\text { Engraving pens } \\
\text { Shoe pounding up machines } \\
\text { Vibratory rollers } \\
\text { Concrete vibrothickeners } \\
\text { Concrete levelling vibrotables } \\
\text { Motorcycle handlebars } \\
\text { Pedestrian controlled machines }\end{array}$ \\
\hline
\end{tabular}

ing a check on the validity of the measurements - for example, the absence of dc shifts. Further, without spectral information, the data are restricted to the current frequency weighting at a time when its appropriateness is increasingly challenged. Modern digital signal processing techniques allow economic calculation and storage of data which has been digitised-this is becoming the method of choice in many situations. With these instruments, alternative evaluations and assessments can be made with no significant increase in time or cost.

\section{Evaluation according to current standards}

It might be beneficial if standards could be clearly identified as providing guidance on either measurement, evaluation, or assessment, but current standards have not yet matured to the appropriate roles. Consequently, they tend to have implications beyond their expected scope. For those applying current standards they may be conveniently grouped as either being concerned with the evaluation of the place of work (International Standard (ISO) 5349, 1986'), or being concerned with the evaluation of a tool (parts of ISO 8662, $1986^{11}$ ).

\section{MEASUREMENT STANDARDS}

Repeatability is a prerequisite for useful measurements of hand-transmitted vibration. Practical use of tools in work is highly variable and therefore not easily repeatable. This leads to two alternative measurement objectives: testing the tool under defined conditions (type testing) or measuring the vibration exposure of a person (or group of people) performing a particular job.

Type testing standards have been evolved for many tools in recent years (table 3 ). The objective is to define a procedure in which a tool can be tested in different laboratories to obtain similar results. Values derived from such tests can therefore be "declared" as an indication of the vibration on such a tool. The first requirement is repeatability: this is achieved by artificially eliminating some of the sources of variability that occur in jobs where the tools are used. The values obtained from these tests should not, therefore, be assumed to indicate with any precision the vibration magnitudes to be expected at work. The measurements on different tools of the same type performing the same test might indicate the relative magnitudes to be expected from these tools at workplaces. However, with some tools, a low magnitude of vibration can be achieved by reducing the performance of the tool. The tool with the lowest magnitude of vibration may not be the most suitable tool and the magnitude measured in the test cannot be assumed to be the same as that in real work. These measurement standards have been stimulated by the requirements of the Machinery Safety Directive of the European Union (discussed later).

The measurement of exposures to handtransmitted vibration at the workplace often requires consideration of a complex exposure pattern. The act of measurement should result in a record of a worker's exposure which is sufficient to perform an evaluation or assessment with a known or estimated accuracy. This requires measurements which allow evaluations representative of the full daily and lifetime exposure; it requires consideration of sampling errors. Sampling procedures for identifying which portions of exposure patterns should be measured are not well developed, so allowing a source of error in subsequent evaluations and assessments.

The ISO $8041,1990^{12}$ defines some characteristics of instrumentation for measuring human exposure to vibration according to other evaluation standards.

The current version of this standard is primarily orientated towards the specification of a commercial meter for the measurement of vibration. British Standard 7482 parts 1 and 2, $1991^{1314}$ is similar to the intended scope of ISO 8041 , but is not concerned with a specific meter. It offers a more complete means of specifying and testing any instrumentation used to measure exposures to hand-transmitted vibration.

\section{EVALUATION STANDARDS}

The ISO 5349, $1986^{\circ}$, the European Standard ENV 25349, $1992^{15}$ and many national standards - for example, American National Standard S3.34, 1986 ${ }^{16}$-use a frequency weighting (called $\mathrm{W}_{\mathrm{h}}$ in British Standard $6842^{10}$ ) to assess the severity of hand-transmitted vibration over the approximate frequency range 8 to $1000 \mathrm{~Hz}$ (fig 2). The same fre- 
Figure 2 Frequency weighting $\left(W_{h}\right)$, (shown here as an asymptotic weighting between 8 and $1000 \mathrm{~Hz}$; when evaluating one-third octave band spectra the frequency range is specified as $6 \cdot 3$ to $1250 \mathrm{~Hz}$. exposure to four hour energy-equivalent frequency-weighted handtransmitted vibration required for the production of finger blanching in $10 \%, 20 \%, 30 \%, 40 \%$, and $50 \%$ of exposed people according to annex $A$ of ISO 5349, 1986.

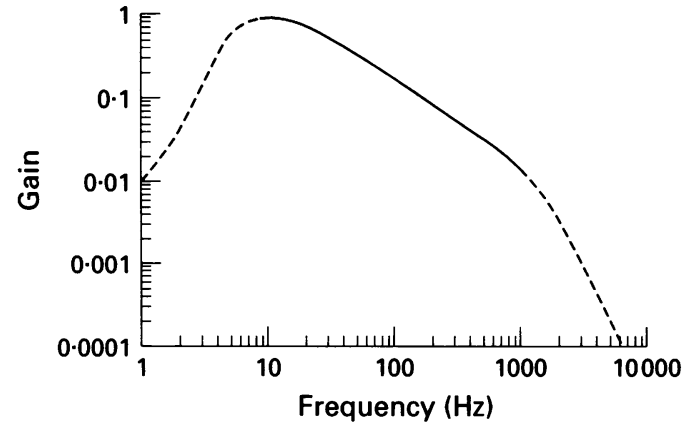

quency weighting, $W_{h}$, is applied to the measurement of vibration acceleration in each of the three axes of vibration at the point of entry of vibration to the hand.

These standards use the concept called "equal energy" so that a complex exposure pattern of any period during the day can be represented by the equivalent value for an exposure of eight hours (four hours in ISO $\left.5349,1986^{\circ}\right)$. For an exposure of duration $t$ to a frequency-weighted rms acceleration $a_{\mathrm{hw}}$ the eight hour energy-equivalent acceleration $a_{\mathrm{hw}(\mathrm{eq}, 8 \mathrm{~h})}$ is given by:

$$
a_{h w(\mathrm{eq}, 8 \mathrm{~h})}=a_{\mathrm{hw}} \sqrt{ }\left(t / T_{(8)}\right)
$$

where $T_{(8)}$ is eight hours (in the same units as $t$ ). The value of $a_{\mathrm{hw}(\mathrm{eq}, 8 \mathrm{~h})}$ is sometimes denoted by $A(8)$.

\section{ASSESSMENT}

All current assessments are based on the expected occurrence of finger blanching (vibration-induced white finger). However, many assume that the prevention of vibrationinduced white finger will be sufficient to prevent the development of other disorders. As explained later, the evaluation method (including the frequency weighting, $\mathrm{W}_{h}$ ) is not based on the development of vibrationinduced white finger. The weighting (and other aspects of the evaluation method) might be justified as a general representation of the dependence of the hand on vibration frequency (and other variables): neither the weighting nor other aspects of the evaluation method are proved to represent the extent to which different frequencies, axes, etc damage the peripheral vascular system and its control mechanisms.

\section{Assessment by ISO 5349}

A relation between years of vibration exposure $E$, the four hour energy equivalent frequencyweighted acceleration $a_{\mathrm{hw}(\mathrm{eq}, 4 \mathrm{~h}}$ ), and the predicted prevalence of finger blanching $C$ was proposed in an annex to ISO 5349, $1986^{\circ}$ (table 4, fig 3):

$$
C=100 .\left[\frac{a_{h w(e q, 4 \mathrm{~h})} \cdot E}{95}\right]^{2}
$$

The values in table 4 and fig 3 refer to frequency-weighted acceleration (referenced to the frequency range 8 to $16 \mathrm{~Hz}$ after passing through the filter shown in fig 2). British Standard $6842,1987^{10}$ offers similar guidance, but is restricted to a $10 \%$ prevalence of vibration-induced white finger. Figure 4 shows how the magnitudes required for a predicted prevalence of $10 \%$ vibration-induced white finger after eight years are assumed to depend on vibration frequency from 8 to $1000 \mathrm{~Hz}$ for exposure durations from one minute to eight hours a day.

The frequency weighting, the time dependency, and the dose-effect information used in ISO $5349,1986^{\circ}$ are based on less than complete information, and such information as exists has been interpolated, extrapolated, and simplified for practical convenience. ${ }^{8}$ Consequently, the percentage of affected people in any exposed group will not always closely

\begin{tabular}{|c|c|c|c|c|c|}
\hline \multirow{2}{*}{$\begin{array}{l}\text { Weighted } \\
\text { acceleration } \\
a_{\text {hw(co, } 4 \mathrm{~h})} \\
\left(\mathrm{ms}^{-2} \mathrm{rms}\right)\end{array}$} & \multicolumn{5}{|c|}{ Percentage of population affected by finger blanching } \\
\hline & $10 \%$ & $20 \%$ & $30 \%$ & $40 \%$ & $50 \%$ \\
\hline $\begin{array}{r}2 \\
5 \\
10 \\
20 \\
50\end{array}$ & $\begin{array}{r}15 \\
6 \\
3 \\
1 \\
<1\end{array}$ & $\begin{array}{r}23 \\
9 \\
4 \\
2 \\
<1\end{array}$ & $\begin{array}{r}>25 \\
11 \\
5 \\
2 \\
<1\end{array}$ & $\begin{array}{r}>25 \\
12 \\
6 \\
3 \\
1\end{array}$ & $\begin{array}{r}>25 \\
14 \\
7 \\
3 \\
1\end{array}$ \\
\hline
\end{tabular}

people according to ISO 5349, $1986^{\circ}$ 
match the values in table 4 or figs 3 and 4 . Also, the number of people affected by vibration will depend on the rate at which people enter and leave a group exposed to vibration.

\section{Machinery Safety Directive}

The Machinery Safety Directive of the European Community (89/392/EEC) states: "machinery must be so designed and constructed that risks resulting from vibrations produced by the machinery are reduced to the lowest level, taking account of technical progress and the availability of means of reducing vibration, in particular at source". ${ }^{17}$ Instruction handbooks for hand-held and hand-guided machinery should specify the equivalent acceleration to which the hands or arms are subjected when this exceeds a stated value (currently a frequency-weighted acceleration of $2.5 \mathrm{~ms}^{2} \mathrm{rms}$ ). The relevance of any such value will depend on the test conditions to be specified in type testing standards (already mentioned and table 3 ). In use, many hand-held vibrating tools can exceed this value. The specified tests do not encompass all realistic exposures and so will not represent the exposures received in some jobs. Also, the different exposure durations and other variables involved in different jobs carry different degrees of risk.

\section{Proposed European Union (EU) Exposure}

Directive

The opening principles of a proposed Council Directive on the minimum health and safety requirements for hand-transmitted vibration are: "Taking account of technical progress and of the availability of measures to control the physical agent at source, the risks arising from exposure to the physical agent must be reduced to the lowest achievable level, with the aim of reducing exposure to below the threshold level ..." ${ }^{18}$

For hand-transmitted vibration, the proposed EU Directive currently identifies a threshold level $\left(a_{\mathrm{hw}(\mathrm{eq}, 8 \mathrm{~h})}=1.0 \mathrm{~ms}^{-2} \mathrm{rms}\right)$, an action level $\left(a_{\mathrm{hw}(\mathrm{eq}, 8 \mathrm{~h})}=2.5 \mathrm{~ms}^{-2} \mathrm{rms}\right)$, and an exposure limit value $\left(a_{\mathrm{hw}(\mathrm{eq}, 8 \mathrm{~h})}=5.0 \mathrm{~ms}^{-2} \mathrm{rms}\right.$. Figure 5 shows the manner in which these eight-hour equivalent magnitudes correspond

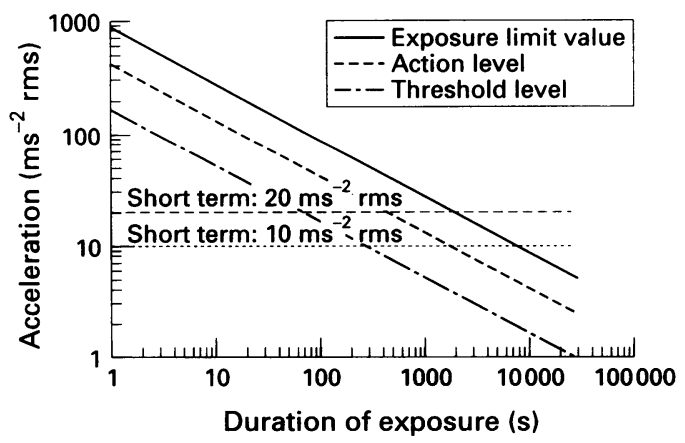

Figure 5 Threshold level, action level, and exposure limit proposed in a draft EC Directive on Physical Agents. As well as these three criteria, effort shall be made to reduce the well as these three criteria, effort shall be made to reduce
hazard when a short term (a few minutes) equivalent acceleration exceeds $10 \mathrm{~ms}^{-2} \mathrm{rms}$. Exposure to a short term (a few minutes) equivalent acceleration equal to or greater than $20 \mathrm{~ms}^{2} \mathrm{rms}$ is considered a hazardous activity. to higher magnitudes at shorter durations. When exposures exceed the threshold level it is proposed that workers must receive information about the potential risk of exposure to hand-transmitted vibration. The action level is intended to identify the conditions in which training in precautionary measures is required, an assessment of the vibration is to be made, and a programme of preventative measures is to be instituted. The proposed Directive also indicates that when the action level is exceeded workers shall have the right to regular health surveillance, including routine examinations designed for the early detection of disorders caused by hand-transmitted vibration If the exposure limit value is exceeded, health surveillance must be carried out and member states of the community will be expected to control the harmful effects.

The extremely high magnitudes for short durations (fig 5) should not be considered to be representative of their safety: these high magnitudes are a consequence of the equal energy concept already described. The proposed Directive identifies exposures "for a short-term (a few minutes) equivalent acceleration equal to or greater than $20 \mathrm{~ms}^{-2}$ " as "activities with increased risk" which must be declared to the authority responsible: member states would be required to ensure that appropriate measures were taken to control the risks associated with these activities. Equipment which transmits to the hand-arm system a short term (a few minutes) equivalent acceleration equal to or greater than $20 \mathrm{~ms}^{-2}$ rms must be marked. For lower magnitudes of vibration, the proposed Directive says: "Where the activity involves the use of work equipment which transmits to the hand-arm system a short-term (a few minutes) equivalent acceleration exceeding $10 \mathrm{~ms}^{-2}$, increased efforts shall be made to reduce the hazard, with priority to the use of low-vibration equipment and processes, including the revision of product design and work practice. Pending the effective implementation the duration of continuous exposure shall be reduced." The ambiguous references to short term and equivalent acceleration leave these as unsatisfactory means of assessing vibration. Vibration exposures are not always statistically stationary: work often includes transient exposures to vibration (and repeated shocks) and variable intermittent periods without exposure to vibration.

The proposed Directive is based on the vector sum (more correctly the root-sums-ofsquares (rss)) of the frequency-weighted accelerations in three axes, although an axis can be omitted if the values are less than $50 \%$ of the values in another axis at the same location. This differs from ISO $5349,1986^{9}$ which is based on the axis having the highest weighted acceleration; however, a forthcoming revision of ISO 5349 is expected to change the evaluation method to the use of rss.

\section{Considerations for the future}

A few variables dominate the current measurement, evaluation, and assessment of occupa- 


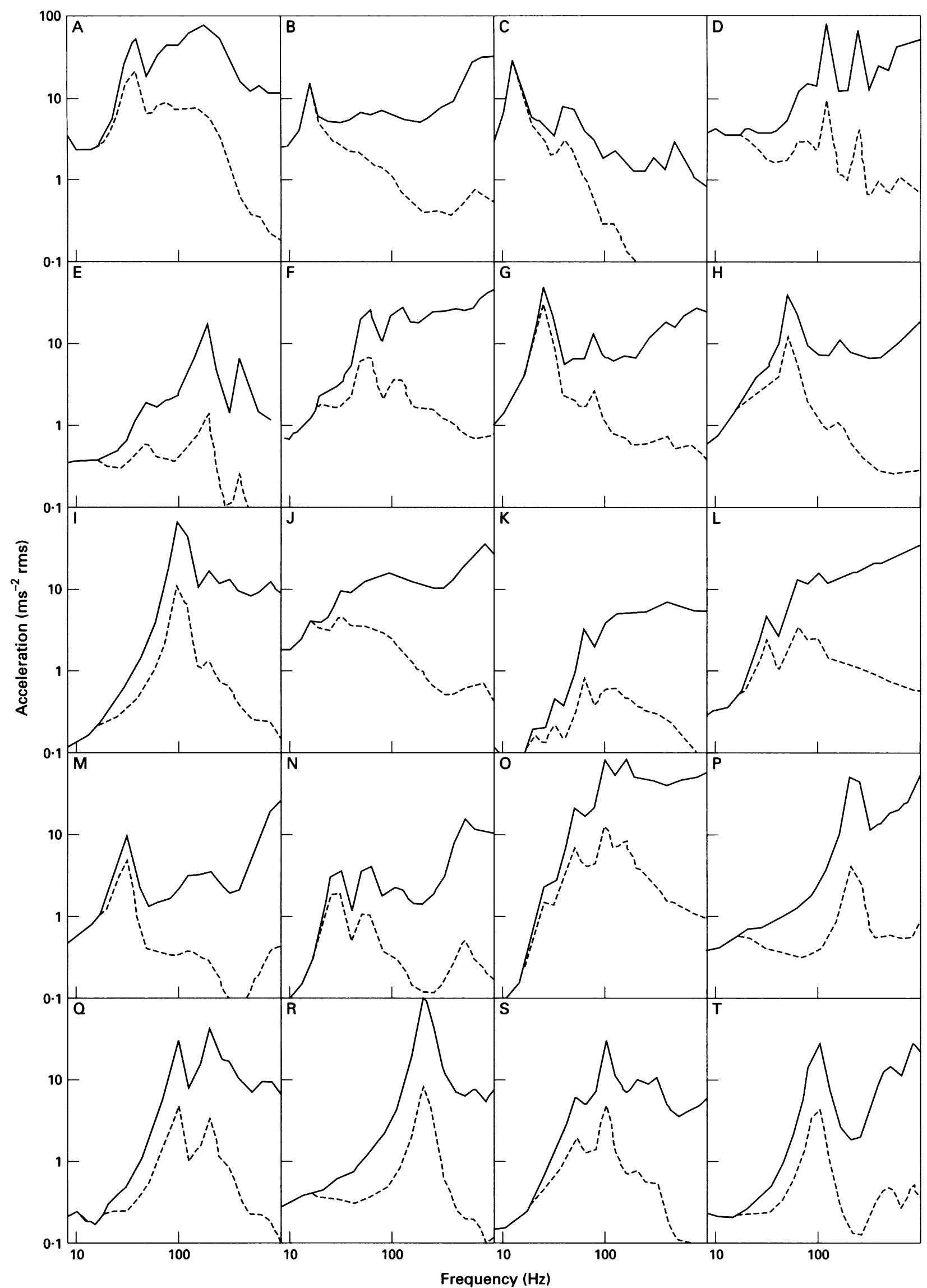

Figure 6 One-third octave band spectra on 20 powered hand tools: - - unweighted spectra; - - - - - weighted spectra; ( $A$ pneumatic rock drill; $B$ pneumatic road breaker; $C$ petrol driven wacker compressing road surface after mending; $D$ non-antivibration chain saw; $E$ antivibration chain saw; $F$ pneumatic metal chipping hammer; $G$ pole scabbler; $H$ needle gun; I random orbital sander; 7 impact wrench; $K$ riveting gun; I dolly used with riveting gun; $M$ nutrunner; $N$ metal drill; $O$ wire swaging; $P$ etching pen; $Q$ electric 9 inch angle grinder; $R$ pneumatic rotary file; $S$ pneumatic 5 inch straight grinder; $T$ pneumatic 7 inch vertical grinder. All spectra from the axis giving the highest weighted acceleration.)

tional exposures to hand-transmitted vibration, yet the manner in which these variables influence the currently standardised method is not widely recognised. They are illustrated here with examples of vibration measurements from an assortment of different tools. There 
Figure 7 Correlation between weighted and unweighted rms acceleration for the 20 spectra shown in fig 6 .

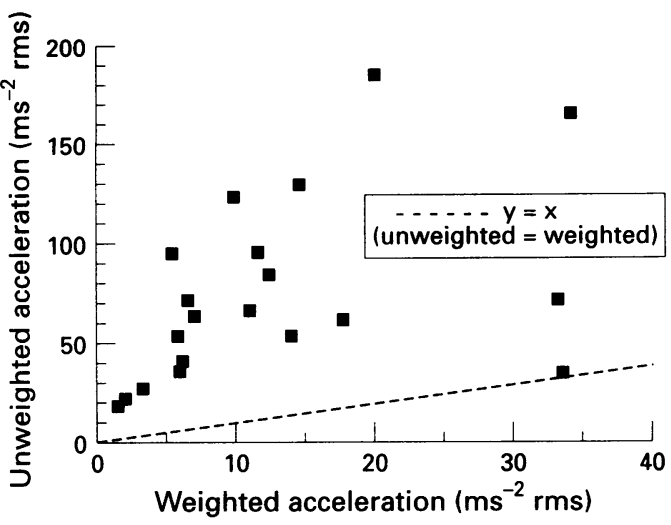

are doubts in several areas, including the validity of the frequency weighting $\left(\mathrm{W}_{\mathrm{h}}\right)$, the appropriateness of the frequency range (8 to 1000 $\mathrm{Hz}$ ), and whether it is sufficient to measure in only the axis with the highest frequencyweighted acceleration.

\section{FREQUENCY WEIGHTING}

Figure 6 shows one-third octave band spectra for 20 tools sometimes associated with vibration-induced white finger. The tools are only partially representative of other types performing a similar function: tools of a specific type tend to have broadly similar spectral shapes although they may have very different vibration magnitudes. Figure 6 shows the weighted spectra formed by applying the ISO 5349 frequency weighting $\left(W_{h}\right)$. The weighting greatly reduces the importance of intermediate and high frequency vibration. However, in many cases the dominant frequencies in the spectra are the same before and after weighting: the frequency weighting changes the magnitude of vibration but often does not greatly alter the frequencies contributing most to the rms magnitude.

Figure 7 shows the correlation between weighted and unweighted acceleration magnitudes for the 20 tools with spectra illustrated in fig 6 . Within tool types, where the magnitude changes between tools but the spectra are similar, a tool with a high unweighted acceleration may be expected to also have a high weighted acceleration. However, across tool types, where the magnitudes and spectra differ, fig 7 shows a poor correlation between unweighted and weighted acceleration. The tools which differ most from the trend are those dominated by low frequencies, so that they have similar unweighted and weighted magnitudes - for example, the wacker-and tools dominated by high frequencies so that the unweighted magnitude is very much greater than the weighted magnitude-for example, swaging. The frequency weighting has therefore changed the rank order of importance of several tools: swaging has the highest unweighted acceleration but the fourth highest weighted acceleration, the wacker has the 16 th highest unweighted acceleration but the highest weighted acceleration.

In so far as tools of a specific type have

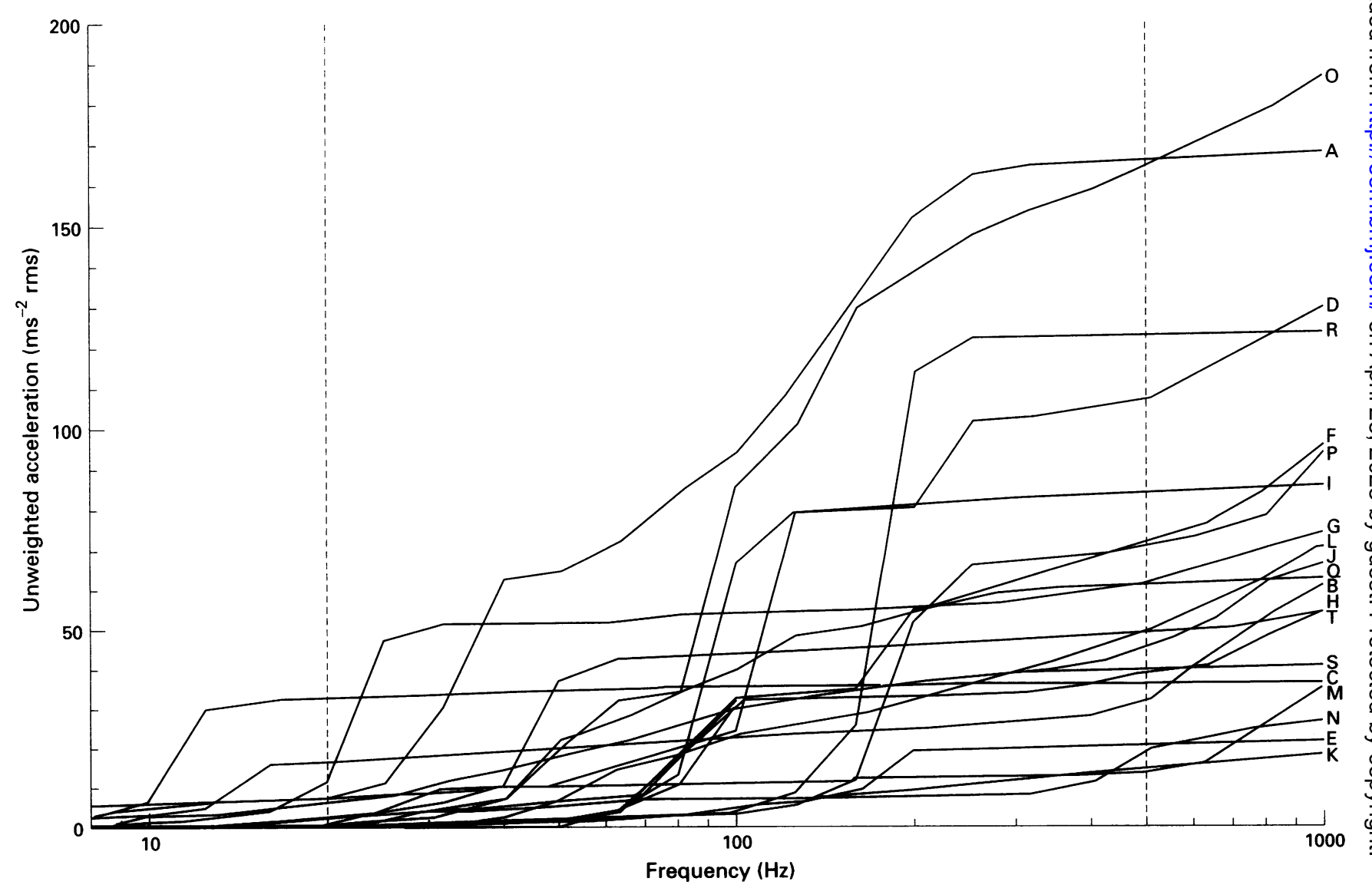

Figure 8 Integrated unweighted spectra for the 20 tools in fig 6: the accumulation of rms acceleration with increase in frequency from 8 to $1000 \mathrm{~Hz}$ (letter denotes the identity of tools as in the caption to fig 6). 


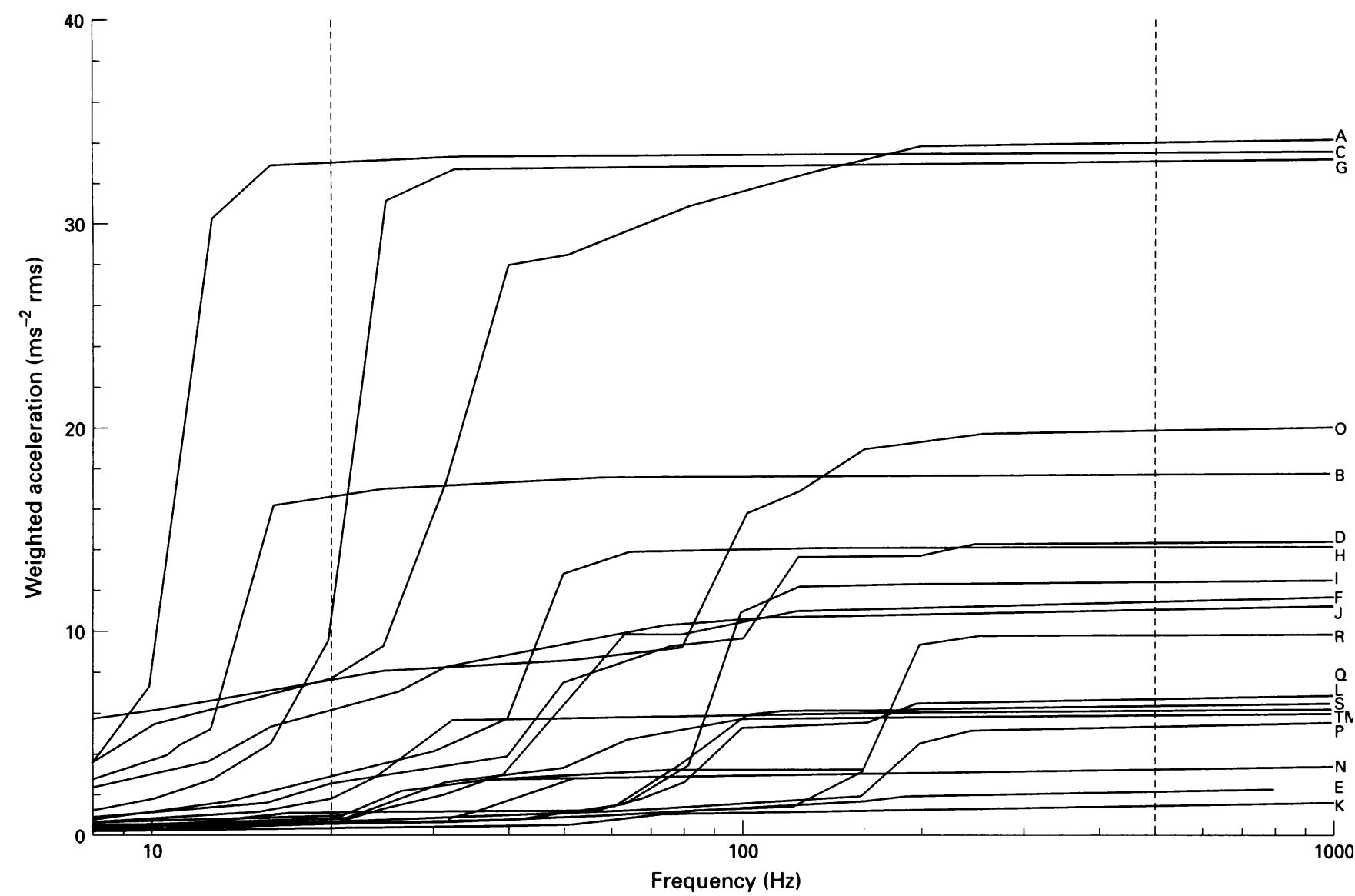

Figure 9 Integrated weighted spectra for the 20 tools in fig 6: the accumulation of frequency-weighted rms acceleration with increase in frequency from 8 to $1000 \mathrm{~Hz}$ (letter denotes the identity of tools as in the caption to fig 6).

broadly similar spectra, the tool of a specific type with the lowest vibration magnitude (weighted or unweighted) will often be the least likely to cause injury, assuming the other variables (duration of exposure, grip, etc) are unchanged. Thus, for manufacturers of specific tools, and those comparing similar tools, a frequency weighting accurately representing the relative risks from different frequencies may not seem necessary. When choosing between tools with different spectra this conclusion cannot be supported: two tools with different spectra but the same weighted acceleration will not have the same unweighted magnitudes and may not have the same potential for causing injury. On this basis, uncertainties about the frequency weighting can be bypassed for some applications if the assessment (for example, predicted prevalence of vibration-induced white finger, or the acceptability of vibration) is made specific to a tool type. ${ }^{19}$ This approach must be closely confined to tools with similar dominant frequencies as the development of an antivibration mechanism for a tool could change its spectral characteristics.

Figure 6 shows that, after frequency weighting, the peaks in the spectra of all tools fall well within the range 16 to $250 \mathrm{~Hz}$. The weighted accelerations are given by the areas under the spectra when they are plotted on appropriate linear scales. The use of logarithmic scales in fig 6 disguises the fact that all of the weighted spectra are dominated by vibra- tion in this narrow range of frequencies. The frequency weighting has effectively limited the range of frequencies contributing to evaluations and assessments to little more than 10:1, even though current standards require measurement of vibration over not less than a 125:1 range, from at least 8 to $1000 \mathrm{~Hz}$.

Figures 8 and 9 show, respectively, the cumulative spectra for unweighted and weighted acceleration for all of the tools shown in fig 6 . In the case of the unweighted spectra (fig 8) the acceleration on some tools (for example, the road breaker, chipping hammer, impact wrench, riveter and dolly, etching pen) increase at frequencies above about $250 \mathrm{~Hz}$. In the case of the weighted spectra, none of the tools show increasing values above 250 $\mathrm{Hz}$ : almost identical values of weighted acceleration would have been obtained by restricting consideration to frequencies below 250 $\mathrm{Hz}$.

At frequencies below $16 \mathrm{~Hz}$, the frequency weighting is such that the rise in the cumulative spectra with increasing frequency is the same for weighted and unweighted spectra. Figures 8 and 9 show that there are large differences between tools in vibration magnitudes at frequencies below $16 \mathrm{~Hz}$.

\section{FREQUENCY RANGE}

Figure 9 seems to show that there is little merit in extending the frequency range above about $250 \mathrm{~Hz}$ when the frequency weighting is used: the weighting reduces the importance of these 

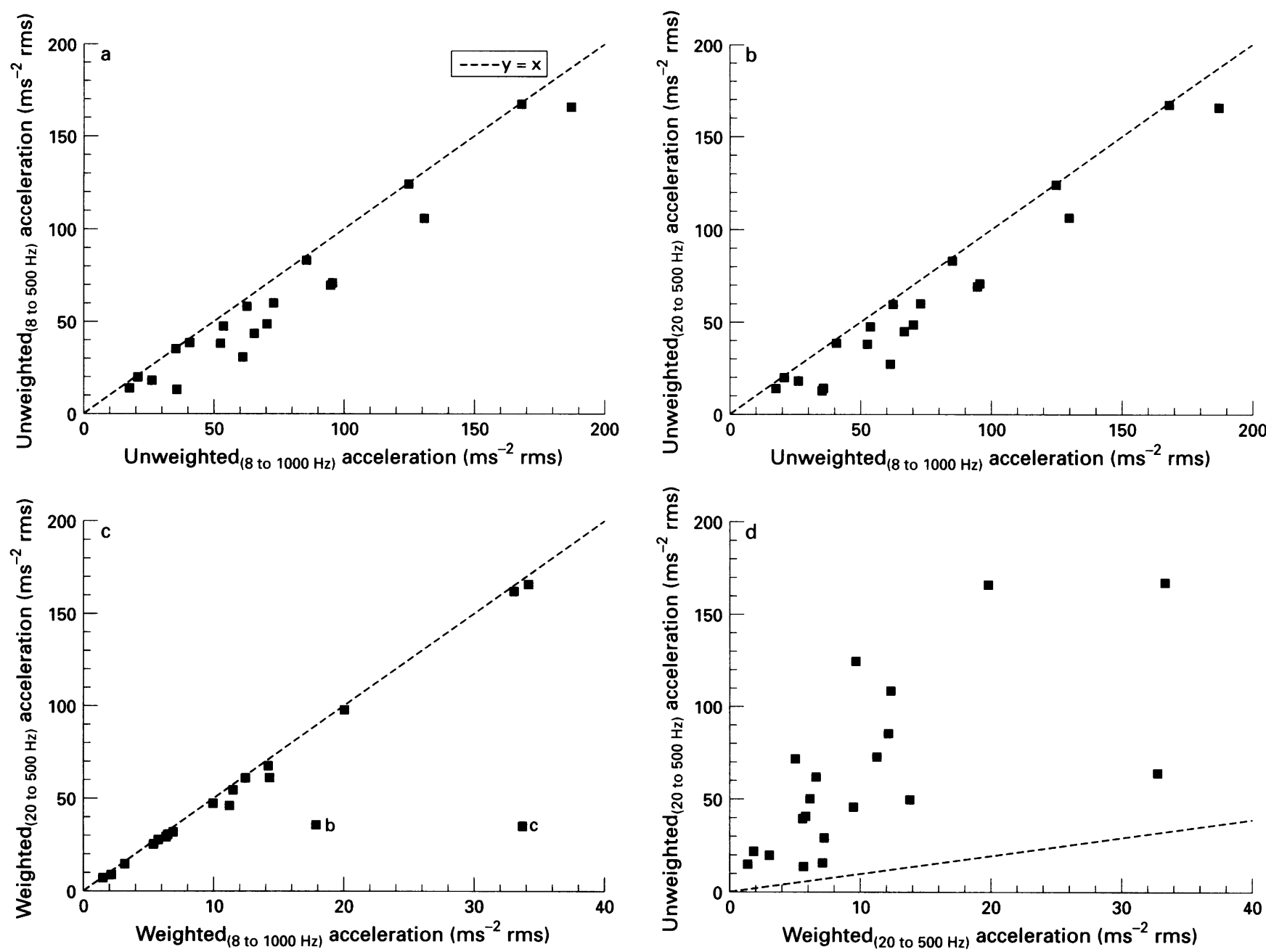

Figure 10 Correlations between various bandwidths of weighted and unweighted rms acceleration for the tools in fig 6: (a) effect of reducing upper frequency to $500 \mathrm{~Hz}$ on unweighted rms acceleration, (b) effect of reducing upper frequency to $500 \mathrm{~Hz}$ and increasing lower frequency to $20 \mathrm{~Hz}$ on unweighted rms acceleration, (c) effect of reducing upper frequency to $500 \mathrm{~Hz}$ and increasing lower frequency to $20 \mathrm{~Hz}$ on weighted rms acceleration, and (d) correlation between weighted and unweighted acceleration in the bandwidth 20 to $500 \mathrm{~Hz}$.

Figure 11 Correlation between rms acceleration in the axis with the highest weighted acceleration with the root-sums-of-squares of accelerations in all three axes (bandwidth 8 to 1000 $\mathrm{Hz}$; no data available for tools $D, E, L$, or $O)$. higher frequencies so much that they contribute little to the resulting value.

Without the frequency weighting there are several tools, the magnitude of which increases as the frequency range is extended above $\mathbf{5 0 0}$ $\mathrm{Hz}$. Some of these - for example, the chipping hammer and the etching pen-have magnitudes which seem to continue to increase through $1000 \mathrm{~Hz}$ : higher magnitudes of unweighted acceleration might be obtained on these tools if the frequency range was extended to even higher frequencies. Even so, Figure 10A shows that, over the 20 types of

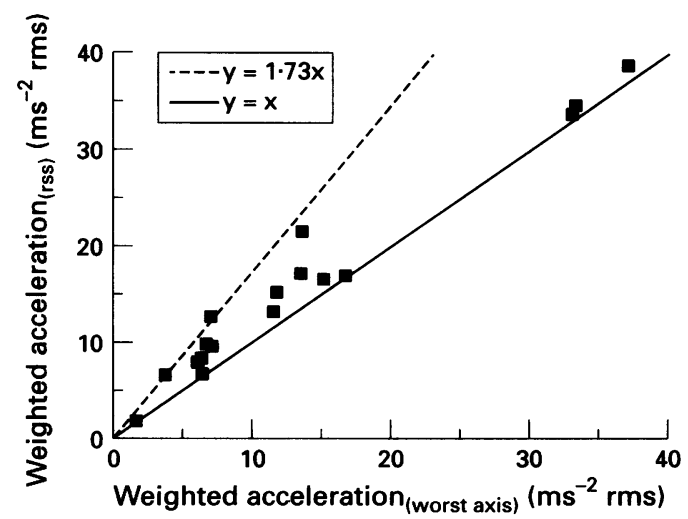

tool, there is a strong correlation between unweighted acceleration magnitudes measured between 8 and $1000 \mathrm{~Hz}$ and those measured between 8 and $500 \mathrm{~Hz}$.

Although at low frequencies several of the tools have high magnitudes below $20 \mathrm{~Hz}$, Figure 10B shows a high correlation between magnitudes measured between 8 and $1000 \mathrm{~Hz}$ and those measured between 20 and $500 \mathrm{~Hz}$ when using unweighted acceleration. The effect of the frequency weighting in reducing the importance of high frequencies is to strengthen this correlation for most tools (fig 10C). However, the two tools with dominant components of vibration below $20 \mathrm{~Hz}$ (the roadbreaker and wacker) give much lower values when frequencies below $20 \mathrm{~Hz}$ are excluded from the analysis.

Figure 10D shows that restricting the frequency range to the band from 20 to $500 \mathrm{~Hz}$ results in a broadly similar order of vibration magnitudes for both unweighted and weighted vibration magnitudes. However, the weighting has raised the relative importance of some tools-such as the scabbler-in which the vibration is dominated by a component at frequencies just above $20 \mathrm{~Hz}$ compared with tools dominated by vibration at higher frequencies. 
DIRECTION

Figure 11 shows the correlation between the use of the "worst axis of vibration" (the vibration in the axis giving the highest magnitudes) and the use of an overall value obtained from the rss of values obtained in all three axes. The maximum difference possible is that the rss values are a factor of $\sqrt{3}(1 \cdot 73)$ greater. It can be seen that in several cases the vibration was dominated by one axis so that there was little difference between considering the worst axis and considering the rss. However, for some tools - for example, the drill and the chipping hammer - the vibration magnitudes in each of the three axes were sufficiently similar for the rss to be almost $\sqrt{3}$ greater than the magnitudes in the worst axis.

\section{Discussion}

FREQUENCY WEIGHTING

The currently used frequency weighting $\left(\mathrm{W}_{\mathrm{h}}\right)$ is based on an extrapolation and a simplification of the contours representing the manner in which the sensations of discomfort caused by vibration of the hand depend on vibration frequency. ${ }^{8}$ At high frequencies the subjective data on which the standardised weighting was based were limited to $300 \mathrm{~Hz}$, and merely extrapolated to $1000 \mathrm{~Hz}$ ! At frequencies above $60 \mathrm{~Hz}$, the shape used in the standardised weighting is such that it gives relatively greater weight than was implied by the subjective data; indeed, at $1000 \mathrm{~Hz}$ the standardised weighting gives a value 16 times greater than would be obtained by linear extrapolation of the experimental data. The extent of the extrapolation, the absence of any consideration of the physiological or pathological effects of vibration, and little consideration of biodynamic responses to vibration, provides a basis for some criticisms of the frequency weighting. Nevertheless, the weighting was adopted by the responsible subcommittee of the International Organisation for Standardisation during the 1970s, and this generated a momentum followed by many national standardisation bodies and, later, by the European Committee for Standardisation (CEN). Although it is not uncommon for the weighting, and indeed, many other aspects of the standards to be questioned, it would be imprudent for potential users of the standards to conclude that doubts allow them to disregard current measurement, evaluation, and assessment procedures, or avoid the actions they imply.

A simple expression of the doubt about the frequency weighting is to enquire whether the relative harm caused by vibration acceleration over the frequency range 8 to $1000 \mathrm{~Hz}$ is better predicted by the frequency weighting, or by assuming that all frequencies cause similar harm. Eliminating the weighting would reduce the importance of low frequency vibration or increase the importance of high frequency vibration. Without the frequency weighting, a theoretical tool $(A)$ with an acceleration $a$ at a frequency of $16 \mathrm{~Hz}$ would be as severe as a theoretical tool $(B)$ with the same unweighted acceleration, $a$, but a frequency of $1000 \mathrm{~Hz}$. With the frequency weighting, tool $A$ would have an acceleration 62.5 times greater than that of tool B and be far more likely to cause injury. However, real tools do not usually have such widely differing frequencies, so that over a range of tools there is a strong correlation between unweighted and weighted accelerations (fig 10D). The correlation increases if frequencies below about $20 \mathrm{~Hz}$ are excluded. Epidemiological studies can only be expected to discern the effect of the frequency weighting when they compare the development of disorders from tools the relative importance of which is appreciably affected by the frequency weighting. Some epidemiological studies have failed to find an improved correlation between vibration exposures and the development of vibration-induced white finger by using the weighting. ${ }^{20}$ For some tools with a predominantly low frequency percussive action, the assessments of vibration according to current standards seem to predict a more rapid development of symptoms than has been found. ${ }^{21}$ Nevertheless, it must be recognised that the dynamic response of the flesh, finger, hand and arm, and the mechanisms of injury must depend on the frequency of vibration and not only the acceleration magnitude. So some frequency weighting is required, even if it is not identical to frequency weighting $\left(W_{h}\right)$ recommended in current standards.

Considerations of the adequacy of the frequency weighting must be coupled to considerations of the different effects of hand-transmitted vibration: it does not seem likely that one weighting will be appropriate to each of the reported groups of effects of vibration (vascular, articular, neurological, etc). The current weighting might be defended as being appropriate to some overall (but undefined) risk of injury from vibration: the adoption of a new weighting optimum for predicting vibration-induced white finger could result in failure to protect against neurological and articular effects of vibration. Studies should therefore seek to uncover the role of vibration frequency in the development of vascular, neurological, articular, and other effects of vibration if the current weighting is to be replaced. Such studies need not be restricted to investigations of prevalence and latency but should also include biodynamic and physiological research. For example, the extent to which the effects of vibration are localised close to the point of contact with vibration may indicate whether high or low frequencies are responsible: effects restricted to the area of contact will be associated with frequencies high enough for the vibration not to be greatly transmitted to distant parts, whereas effects occurring away from the contact area are likely to be caused by lower frequencies. The localisation may be ascertained by study of affected people whereas the distinction between high and low frequencies may be discerned by biodynamic experiments.

Although modifications to the frequency weighting, and even its abolition, have been proposed, the ISO subcommittee responsible 
for ISO 5349 is not currently persuaded that the evidence is sufficient to identify the form of any improved frequency dependence. In the longer term, changes can be anticipated. It is therefore desirable to obtain and report vibration measurements in a form which allows the subsequent application of other frequency weightings. ${ }^{22}$

\section{FREQUENCY RANGE}

It has been proposed that the frequency range be extended above $1000^{23-26}$ and that special consideration be given to impulsiveness. ${ }^{27}$ This would require a change to the measurement method and also a change to the evaluation method.

It is not simple to measure vibration on handles at high frequencies. The methods of attaching accelerometers to handles used in some studies are not even valid at frequencies as high as $1000 \mathrm{~Hz}$ : the mounting sometimes has a resonance affecting measurements below $1000 \mathrm{~Hz}$, and the mass of the accelerometer may affect movements of the handle at these high frequencies. At high frequencies, many handles will have modes of vibration such that the vibration magnitude will vary from one location to another. An extension of the measurement range to 2000 or $4000 \mathrm{~Hz}^{23}$ is likely to increase errors in reported measurements due to artefactual resonances. Even if some tools have vibration at frequencies greater than $1000 \mathrm{~Hz}$ that can cause disorders, it seems likely that the disorders currently caused by many tools, possibly most tools, arise from lower frequencies. In view of the considerable difficulties, and consequent errors, introduced by the measurement of higher frequencies, some scientists doubt whether current evidence is sufficient to justify a requirement to measure at frequencies above $1000 \mathrm{~Hz}$ for all tools.

Measurement difficulties are not sufficient in themselves to imply that the high frequencies are not important, although the currently used frequency weighting does imply little importance to the high frequencies. Figures 6 , 8 , and 9 indicate that weighted values would not be changed by increasing the frequency range beyond $1000 \mathrm{~Hz}$. Consequently, an extension to the frequency range also implies a change to the frequency weighting. There seems to be no basis for selecting any particular weighting so it may be unwise to define a weighting arbitrarily: to collect data on the characteristics of high frequency vibration on tools is a preferable initial step.

Although some tools may have magnitudes of acceleration at high frequencies which are sufficient to cause injury, it seems doubtful whether frequencies above $1000 \mathrm{~Hz}$ are a major contributor to the effects of vibration (particularly vibration-induced white finger) from the use of most tools (table 1). On this basis, whereas it currently seems reasonable to advocate the measurement of unweighted acceleration to frequencies above $1000 \mathrm{~Hz}$ when this is practicable, it does not yet seem necessary to include such measurements in the assessment of vibration. As more experience is gained on the measurement difficulties at high frequencies, and as more experience accumulates about the importance of the higher frequencies, so their role in revised dose-effect guidance may be reconsidered.

There are problems introduced by the inclusion of frequencies as low as $8 \mathrm{~Hz}$. Voluntary movements when controlling a tool, movements of cables, and other causes of low frequency problems-for example, dc shiftcan artificially raise the measured vibration magnitudes. Restricting the lower frequency to, say, $20 \mathrm{~Hz}$ would reduce the importance of these problems. Although there is little reason to suppose that these low frequencies are a normal cause of vibration-induced white finger, high magnitudes of vibration below $20 \mathrm{~Hz}$ must be undesirable. As long as evaluation procedures are based on a single frequency weighting, it may be warranted to include low frequencies within the bandwidth of the measurement and evaluation procedures. Further consideration of the extent of low frequency vibration on tools may help to discern the need for limitations at low frequencies.

\section{MAGNITUDE}

The dose-effect guidance given in an annex to ISO $5349,1986^{\circ}$ indicates that the incidence of finger blanching increases in proportion to the square of the vibration magnitude, if other variables are unchanged:

$$
C=\left[\frac{a_{h w} \cdot E}{9 \cdot 5}\right]^{2} \cdot \frac{t}{T_{(4)}}
$$

where: $C=$ prevalence of vibration-induced white finger (expressed as a percentage); $a_{\mathrm{hw}}$ $=$ frequency-weighted acceleration $\left(\mathrm{ms}^{-2} \mathrm{rms}\right)$; $E=$ years of regular exposure to vibration; $t=$ duration of daily exposure (in same units as $\left.T_{(4)}\right) ; T_{(4)}=$ four hours (in same units as $t$ ).

This relation between vibration magnitude and the development of vibration-induced white finger seems to have arisen from considerations other than direct evidence of this relation. The full implications are worthy of consideration. The heavy weighting placed on acceleration (as opposed to duration of daily exposure) encourages lower magnitudes of vibration. However, the weighted magnitude is affected by the frequency weighting: if the weighting is slightly in error the predicted prevalence will be in even greater error. The dose-effect guidance is restricted to the range $10 \%$ to $50 \%$ in ISO $5349,1986^{9}$ corresponding to a $2 \cdot 2: 1$ range of vibration magnitudes. For a particular duration of exposure, a $2 \cdot 2: 1$ increase in vibration magnitude (or a $2 \cdot 2: 1$ error in the frequency weighting) would increase the vibration from being a problem barely greater than the background level of vascular problems to more than half of the exposed people developing the condition. It is inconceivable that the frequency weighting is accurate to within $2 \cdot 2: 1$ over the frequency range 8 to $1000 \mathrm{~Hz}$. Consequently, in studies in which the prevalence of vibration-induced white finger has been correctly predicted by the procedures of ISO $5349,1986^{9}$ this must have arisen from a chance (or restricted) combination of variables: such findings do not ver- 
ify the full process of measurement, evaluation, and assessment defined in the standard.

In ISO $5349,1986^{9}$ vibration magnitude is assumed to be measured by its rms value. This assumes a relation between the acceleration magnitude and the square root of the duration of exposure. The relation is used to obtain an equivalent four hour vibration magnitude for any combination of continuous, intermittent, or impulsive events. It seems unlikely that such a simple relation will hold over the very wide range of magnitudes and durations involved in hand-transmitted vibration. Research must explore the applicability of this relation as much as the relations between the magnitude and frequency of vibration and the years of exposure. As with whole-body vibration, this time-dependency seems to allow excessive magnitudes with short durations of exposure: it may therefore underestimate the severity of vibrations containing occasional high magnitude shocks. ${ }^{8}$

The possibility of a threshold level for the occurrence of vascular disorders has been suggested..$^{20} \mathrm{~A}$ threshold might vary from person to person and depend on some other variables, but above the threshold the outcome would be primarily related to duration of exposure rather than vibration magnitude. The concept might be consistent with some epidemiological data, but should currently be considered a hypothesis suggesting specific lines of investigation. The concept could lead to different types of prevention than those implied by a continuous relation between the incidence of vibration-induced white finger and the square of the acceleration magnitude.

\section{DIRECTION}

There has been inconsistency between standards in whether the vibration should be assessed only in the direction with the highest magnitude (ISO $5349,1986^{\circ}$ ) or whether the weighted magnitudes in all three axes should be summed together, to form the rss (ISO $\left.7505,1986^{28}\right)$. The rss is a higher value, although for many tools the increase is not great compared with the likely errors caused by the choice of frequency weighting and the frequency range (fig 10D). However, a difference in magnitude of $\sqrt{3}: 1$ corresponds to a difference of 3:1 in the predicted prevalence of vibration-induced white finger according to ISO $5349,1986 .{ }^{9}$ Considerations of uniformity are leading to the use of the summation method in most standards and this is also advocated in the proposed Exposure Directive from the EU. The method is also consistent with results of some studies of acute effects of hand-transmitted vibration. ${ }^{29}$ Even so, the use of only a single axis is advocated for some type testing of specific tools (parts of ISO 8662 , $\left.1986^{11}\right)$. It has been argued that the use of the rss has the merit of avoiding erroneously low values arising from misidentifying the worst axis.

Of greater interest, but rarely debated, is the assumption that all three axes of vibration are equally important in causing injury. The transmission of vibration into the tissues of the fin- gers and hand, and their transmission to other parts of the body are different for motion normal to the surface as opposed to motion in the shear axes. ${ }^{3031}$ The sensations caused by the vibration also differ in each axis. This suggests that a different weighting should be applied to each of the axes before their effects are compared or combined. On this basis, it could be argued that the use of the rss with the same weighting for each axis will conceal the true vibration severity and introduce errors into some assessments.

When a hand is wrapped around the handle of a tool, the vibration in one direction can be normal to one part of the hand and tangential to another part of the hand. It would be impractical in these situations to use different weightings for different locations of the hand. On some tools, however, the dominant direction is clearly defined and a handle might be designed so that the vibration predominantly entered the hand in a shear direction, rather than the normal direction. This might be expected to alter the hazards associated with the vibration, but this would not be reflected in the measured severity of the rss. The trend towards the use of the rss method has implications for $(a)$ tool designers, $(b)$ those interpreting epidemiological data, $(c)$ the design of instruments used to assess vibration on tools, (d) the effectiveness of gloves in attenuating vibration, and (e) dose-effect guidance which might differ from that appropriate for single axis measurements.

DURATION OF EXPOSURE

In ISO $5349,1986^{9}$ the predicted incidence of finger blanching increases in linear proportion to the duration of exposure to vibration during the day, but increases in proportion to the square of the duration of exposure to vibration expressed in years (equation 3). The influence of years of exposure was derived from "average latency" data, whereas the effect of hours of exposure arose from a convenience rather than evidence that this was the case. ${ }^{32}$ The linear relation between years of exposure and acceleration magnitude seems to be consistent with some epidemiological studies with percussive and rotary quarry tools and with chain saws. ${ }^{33} 34$ It is incontrovertible that the prevalence and severity of vascular and neurological effects of vibration increase with increases in the total duration of exposure to vibration. It is not so evident that there is a large difference between daily and yearly exposures.

The effect of duration of daily exposure is important as reducing duration of exposure will sometimes be more practical than reducing vibration magnitude. Equation 3 shows that a fourfold reduction in duration of daily exposure, or a twofold reduction in years of exposure, is required to achieve the same as a twofold reduction in vibration magnitude. Equation 3 therefore contains unfounded speculation that long daily exposures for a few years will be less harmful than the same total duration of exposure spread out over more years.

The ISO $5349,1986^{9}$ specifies how expo- 
sures to different magnitudes and durations of vibration during the day should be accumulated so as to determine an equivalent daily exposure. There is no defined procedure for accumulating exposures which vary between days or over weeks or years. For many people, exposure to hand-transmitted vibration varies from job to job or with seasonal changes. It might be thought appropriate to assess the severity of such exposures by either summing the fractions of yearly exposure or summing the prevalences arising from each exposure, but these give different results. Mathematically, the most convenient approach would be based on total hours of exposure so that the same time dependency was used for exposures within the day and across years. However, this is also unsubstantiated and gives results very different from those implied by equation 3 .

Current standards offer no alleviation of the rated severity of exposures to hand-transmitted vibration from rest periods, either breaks during the day or periods away from exposure during the year. During the day, the total hours of exposure are used in the assessment, irrespective of whether the exposure is intermittent or continuous. During the year the method is unclear, but often a full year will be counted irrespective of days, weeks, or months without exposure to vibration. With the importance of the years of vibration exposure in equation 3 , and the lessening of symptoms of vibration-induced white finger sometimes experienced after absence of exposure, this places a high emphasis on years in a job.

So far, methods of predicting the percentage of people who will develop vibrationinduced white finger have been based on cross sectional epidemiological studies. However, such studies do not easily surrender the required data on duration of exposure. The historical exposure of people cannot normally be estimated with any precision. Also, there is a need to distinguish between the mean latency (duration between onset of exposure and onset of symptoms) for an affected percentile in the published data and the mean exposure time required for the same percentile to develop the condition.

FORCE AND CONTACT AREA

Consideration of the appropriate frequency weighting should allow recognition that the same weighting may not be appropriate for vibration entering the fingers as for vibration entering the hands. Further, as hand-transmitted vibration causes central as well as local effects, ${ }^{35}$ it could be argued that exposure of two hands to vibration is more severe than the exposure of a single hand. Current standards and guidance, including the proposed EU Exposure Directive, assume that it is sufficient to consider only the hand exposed to the highest magnitude of vibration.

Current methods of evaluation make no distinction between high and low contact forces, or between a force applied by a large area--for example, the palm of the hand-or a small area-for example, the finger tips. The trans- mission of vibration into the body and the transmission of vibration through the body are affected by these factors in a complex manner which depends on the vibration frequency and vibration direction. The local circulation may also be influenced by an excessive grip force.

A grip force as low as possible consistent with safe tool operation may be advocated in many cases. Increasing the contact area so as to minimise contact pressure might also be beneficial. These factors have implications for the design of tools, especially handles. Methods for the standardised measurement and evaluation of these factors are required, and experience with the application of these methods may be needed before consideration of how they should influence assessments of vibration exposures.

POSTURE

As hand-transmitted vibration can result in a disorder associated with reduced peripheral circulation, other factors which impede circulation require consideration. Work with the hands above the head, high grip forces and, possibly, prolonged work in a sedentary posture may reduce peripheral circulation. Again, a simple means of assessing these factors is required before their measurement can be advocated and they can influence the assessment of exposures to hand-transmitted vibration.

\section{TEMPERATURE}

Body temperature has long been assumed to play a part in the development of the vascular effects of hand-transmitted vibration (vibration-induced white finger). Although the evidence is not unequivocal, there seems little scope for advocating anything other than a warm environment consistent with maintaining good circulation. However, the non-vascular effects may not be alleviated by warmth and so maintaining a warm environment cannot be considered sufficient to prevent disorders caused by hand-transmitted vibration. Although warm and dry hands can easily be recommended (including the provision of suitable gloves) this does not affect the assessment of the vibration severity, although it may lessen symptoms and might lessen some of the harmful effects of hand-transmitted vibration.

\section{SUBJECT VARIABILITY}

There is a large variability between people in their susceptibility to the effects of hand-transmitted vibration. Among users of the same tools the effects may appear in some within a year or so but not after 20 or 30 years in others. Study of the differences between people may provide some clues as to the relative importance of some causal variables already mentioned, and others, including constitutional variables, not yet incriminated in the development of disorders associated with hand-transmitted vibration.

The variability in susceptibility to the effects of hand-transmitted vibration is currently reflected in the increased percentage predicted to have vibration-induced white finger as 
either the duration of exposure or the vibration magnitude increases. British Standard 6842, $1987^{10}$ and a recently proposed revision to ISO 5349 , restrict the dose-effect guidance to those conditions causing a $10 \%$ incidence of vibration-induced white finger. Continuous doseeffect guidance, such as that in equation 3, should be based on evidence of the relations between the four variables. A $10 \%$ criterion reduces the variables by one but also changes the justification to a simple prediction of whether symptoms are likely: an action level. A $10 \%$ prevalence of vibration-induced white finger is then justified as being at least double the prevalence of similar symptoms in a control group.

Observation of affected workers shows that some may develop neurological disorders while others may develop vascular disorders. Further study of the factors associated with the differences, including the elaboration of improved objective indicators of disorders, may help to understand the causal mechanisms behind these effects.

\section{OTHER VARIABLES}

For a complete understanding of the form and mechanisms of disorders caused by handtransmitted vibration it may be necessary to consider other variables when assessing exposures to vibration at the workplace, or the severity of vibration on specific tools. With present understanding, the above catalogue of variables is already overly complex.

In concept, a more complete dose-effect relation could be given by combining the various variables into one measure. ${ }^{19}$ Although this may provide a useful philosophical framework it may not be helpful when assessing vibration in specific situations. The process of forming an overall equation giving a method of combining the effects of different variables involves considering whether variables have continuous or discrete on-off effects, and whether variables interact. A recognition of potential complexity is desirable, but the application of knowledge to specific situations must be simple. An elegant simplicity might be artificially created: its form being enhanced by understanding that greater accuracy of application is not automatically achieved through greater complexity.

\section{INERTIA AND MOMENTUM}

Travellers seeking directions must continue from where they find themselves by using the available paths. The map maker may stand aside and consider new journeys in the future: he will be influenced by the impressions of past travellers but concerned not to confuse those familiar with the route: only small changes may be possible.

The enormous number of standards referring to the evaluation methods-for example, the frequency weighting and frequency rangeoriginally defined in ISO $5349,1986^{\circ}$ must impede changes to the standard. A change to the weighting, the frequency range, or to the use of rss alters the effective magnitude and therefore changes the assessment of vibration on tools. Any such change will also influence the claimed effectiveness of potential protective measures, such as vibration isolation devices or gloves.

The ISO 5349, $1986^{9}$ has provided a method of evaluating hand-transmitted vibration and undoubtedly contributed to a reduction in hazardous exposures. For some, this success is a sufficient justification for its publication and even its retention. Others might argue that greater success would arise from an improved standard based on repeatable data obtained by scientific method, rather than on the consent of the members of a small committee. Certainly, an ISO subcommittee is able to promulgate a new standard on the basis of insufficient objections rather than as a result of reasoned argument: the reasoning behind many standards does not reach the level of rigor needed for a paper in a reputable scientific journal. At a time when there is little knowledge, this arbitrary decision making produces a standard when none may be possible by reasoned argument. When there is knowledge the approach is irresponsible if it ignores or alienates those with expertise. The future will show how measurement and evaluation standards and assessment guidelines have followed the path uncovered by advancing knowledge of the relations between handtransmitted vibration and various signs and symptoms.

\section{Conclusions}

There are many challenges remaining in the measurement, evaluation, and assessment of hand-transmitted vibration. The mechanism of injury is not known and even the full range of injuries is not agreed. It is therefore not surprising that methods of predicting the effects of vibration from measures of exposure to vibration have significant uncertainties.

At the time of writing there is a need to balance two opposing forces. On one side it is necessary to express clearly that hand-transmitted vibration does cause injury and that the measurement and evaluation of vibration exposures according to current methods will usually form a significant and useful part of a preventive programme. On the other side there is the need to identify areas in which current measurement and evaluation procedures require improvement. In some cases this may be achieved by a greater coherence between science and the standards. ${ }^{32}$ In other areas there is a need for research leading to new understanding and consequent changes to both thinking and standards. This desire for progress is the raison d'être of the scientist: it should not be used as an excuse for inaction when the measurement and evaluation of vibration with currently standardised methods may reasonably be expected to be beneficial.

Current uncertainties in the relation between vibration and its effects have an influence on the collection of data on which future standards are to be based. Scientific investigations must reach outside the web formed by current standards if they are to make new discoveries: the truth is laid down in nature 
and not in standardisation committees Standardised methods of measurement and evaluation should not be confined by crude and approximate assessment methods: they should allow, assist, and encourage the collection of improved data on human exposure to hand-transmitted vibration. This requires the standardisation of methods of collecting and reporting the spectral, axial, and temporal characteristics of vibration exposures, and other variables, over a wide range of conditions.

The analyses of tool vibration presented in this paper suggest that when using the current frequency weighting $\left(W_{h}\right)$ it is likely to be sufficient to restrict the measurement of vibration to frequencies below about $250 \mathrm{~Hz}$. Without the frequency weighting, many tools have significant vibration at frequencies above $250 \mathrm{~Hz}$, but only a few would be greatly underestimated with an upper limit of $500 \mathrm{~Hz}$ rather than the current $1000 \mathrm{~Hz}$ limit. A significant lowering of the upper frequency could appreciably assist the method of measuring handtransmitted vibration, or even change the manner in which this is performed. At low frequencies there are arguments for excluding frequencies below about $20 \mathrm{~Hz}$, especially when attempting to predict the vascular effects of vibration. Considering the nature of the vibration on many tools, and currently available epidemiological data relating to vibrationinduced white finger, it is difficult to see a justification for the current combination of the frequency range $(8$ to $1000 \mathrm{~Hz}$ ) and the frequency weighting $\left(W_{h}\right)$. It seems that either the frequency range should be reduced or the measurements should be obtained without this frequency weighting: epidemiological and experimental studies are required to determine the appropriate combination of frequency range and frequency weighting.

Uncertainties in the effects of some variables may have a large effect on the performance of some proposed preventative procedures. For example, in the past, few scientists have advocated antivibration gloves as a useful solution to the effects of hand-transmitted vibration. Gloves may attenuate high frequencies of vibration but do not attenuate the low frequencies. It is argued that most tools are dominated by low frequencies at which such gloves have little beneficial effects. In part, this arises from the influence of the frequency weighting used in ISO 5349, $1986^{\circ}$ (fig 2). The use of unweighted acceleration over the range 8 to $1000 \mathrm{~Hz}$ would increase the perceived effectiveness of such gloves. An extension of the frequency range to frequencies above $1000 \mathrm{~Hz}$ (or raising the low frequency limit to, say, $20 \mathrm{~Hz}$ ) could further increase the apparent value of gloves. While new standards for antivibration gloves (for example, ISO $10819,1996^{36}$ ) make use of the current frequency weighting, their future evolution should include consideration of the consequences of changes to the frequency weighting.

In the past, a lack of knowledge has allowed the production of standards for the measure- ment, evaluation, and assessment of vibration based on committee consensus. Consultation with the scientific literature, or carefully argued debate over the interpretation or application of published data is not always part of the process in forming a personal, national, or international view on human vibration standards. It is to be hoped that future standards will identify the foundations on which they are offered and that this will include information published in scientific, medical, and engineering journals available for peer review. When the limitations to knowledge prevent consensus based on such foundations, the decisions and their justification should be declared. In all cases, methods proposed by standardisation committees would benefit from trial application and thorough analysis before they are offered for ritual approval by member countries. Extraordinary as it may seem, distinguished bodies have been prepared to agree to proposed new vibration standards without being aware of the basis on which they have been formulated, without seeing any example of the application of the proposed standard, and without being provided with information on the consequences of the standard. This, and the anonymity involved in the production of standards, allows the publication of arbitrary standardised methods without this being made clear to users of a standard.

1 Departmental Committee on Compensation for Industria Diseases. Report of the departmental committee on compensation for industrial diseases. London: HMSO, 1907 Cd3495.

2 Corsini A. Gli strumenti ad aria compressa in rapporto all'igiene dell'operaio. Il Ramazzini 1907;2:437-52.

3 Loriga G. Il lavoro con i martelli pneumatici. (The use of pneumatic hammers.) Boll Ispett Lavoro 1911;2:35-60.

4 Cargile $\mathrm{CH}$. Raynaud's disease in stone cutters using pneumatic tools. ҰAMA 1915;65:582.

5 Bureau of Labour Statistics. Industrial accidents and hygiene series No 19. Effect of the air hammer on stone cutters. Final report, bulletin 236. Washington, DC: BLS, 1918:PB-254-601.

6 Industrial Injuries Advisory Council, Department of Health and Social Security. Social Security Act 1975: Vibration white finger, London: HMSO, 1981: Cmnd 8350.

7 Department of Social Security, Social Security Administration Act 1992. Hand arm vibration syndrome (vascular and neurological components involving the fingers and thumb), Report by the Industrial Injuries Advisory Council in accordance with Section 171 of the Social Security Administration Act 1992 on the question Security Administration Act 1992 on the question whether hand arm vibration syndrome shoul

8 Griffin MJ. Handbook of human vibration, London: Academic Press, 1990

9 International Organisation for Standardisation. Mechanical vibration-guidelines for the measurement and the assessment of human exposure to hand-transmitted vibration. Geneva: ISO, 1986:5349.

10 British Standards Institution. Measurement and evaluation of human exposure to vibration transmitted to the hand. London: BSI, 1987:6842.

11 International Organisation for Standardisation. Measurement of vibrations in hand-held power tools-Part 1: general. ment of vibrations in hand-held pow

12 International Organisation for Standardisation. Human response to vibration-measuring instrumentation. Geneva: ISO, 1990:8041.

13 British Standards Institution. Instrumentation for the measurement of vibration exposure of human beings. Part 1. Specification for general requirements for instrumentation for measuring the vibration applied to human beings. British Standard. London: BSI, 1991:7482 Part 1.

14 British Standards Institution. Instrumentation for the measurement of vibration exposure of human beings. Part 2. Specification for instrumentation for measuring vibration transmitted to the hand. London: BSI, 1991:7482 Part 2.

15 European Committee for Standardisation. Mechanical vibration-Guidelines for the measurement and the assessment of human exposure to hand-transmitted vibration. Brussels: ENV, 1992:25349.

16 American National Standards Institute. Guide for the mea- 
surement and evaluation of human exposure to vibration transmitted to the hand. New York: ANSI 1986:S3.34. (ASA 67.)

17 Council of the European Communities. On the approximation of the laws of the member states relating to machinery. Council Directive 89/392/EEC. Brussels: Official Journal of the European Communities, 1989: June, 9-32.

18 Commission of the European Communities. Amended proposal for a Council Directive on the minimum health and safety requirements regarding the exposure of workers to the risks arising from physical agents-Individual Directive in relation to Article 16 of Directive 89/391/EEC. Brussels: Official Journal of the European Communities, 1994: No C 230, 19.8.94, 3-29.

19 Griffin MJ. Foundations of hand-transmitted vibration standards. Nagoya f Med Sci 1994:57(suppl):147-64.

20 Nelson CM, Griffin MJ. Comparison of predictive model for vibration-induced white finger. In: Dupuis $\mathrm{H}$, Christ E, Sandover J, Taylor W, Okada A, eds. Proceedings of the Eth International Conference on Hand-arm Vibration. 6th International Conference on Hand-arm Vibration. 53754).

21 Walker DD, Jones B, Ogston S, Tasker EG, Robinson AJ. A study of white finger in the gas industry. $\mathrm{Br} \mathcal{F}$ Ind $\mathrm{Med}$ 985;42:672-7.

22 Nelson CM, Griffin MJ. Improving the measurement and evaluation of hand-transmitted vibration. In: Dupuis $\mathrm{H}$ Christ E, Sandover J, Taylor W, Okada A, eds. Proceedings of the 6th International Conference on Hand-arm (HVBG, D-53754)

23 National Institute for Occupational Safety and Health Criteria for a recommended standard: occupational exposure to hand-arm vibration. Cincinnati: US Department of Health and Human Services, National Institute for Occupational Safety and Health, DHHS (NIOSH) Occupational Safety and
1989. (Publ No 89-106.)

24 Pekkarinen J, Starck J, Pyykkö I. High-speed digital method to measure impulsive hand-arm vibration. Vibration at work. In: Proceedings of 3rd International Symposium of the International Section of the ISSA for Research on Prevention of Occupational Risks. Vienna, 19-21 April, 1989, 47-50.

25 Lundström R. Health effects of hand-arm percussive tools. An overview. In: Okada A, Taylor W, Dupuis H, eds Proceedings of the 5th International Conference on HandArm Vibration. Kanazawa, 23-26 May, 1989. Kanazawa: Kyoei Press, 1990:113-6.
26 Dandanell R, Lundström R. Alternative methods for assessment of riveting hammer vibration, In: Dupuis $\mathrm{H}$ Christ E, Sandover J, Taylor W, Okada A, eds. Proceedings of the 6th International Conference on Hand-arm Vibration. Bonn, 1992. Sankt Augustin: 1993:925-31. (HVBG, D-53754.)

27 Starck J, Pyykkö I. Impulsiveness of vibration as an additional factor in the hazards associated with handadditional factor in the hazards associated with hand323-6.

28 International Organisation for Standardisation. Forestry machinery Chain saws-Measurement of hand-transmitted vibration. Geneva: ISO, 1986:7505.

29 Stelling J, Dupuis H. Beanspruchung des Hand-Arm-System durch multiaxiale mechanische Schwingungen. (Stress to the hand-arm system caused by multiaxial mechanical vibration.) Hauptverband der gewerblichen Berufsgenossenschaften, 1995.

30 Reynolds DD. Hand-arm vibration: a review of three years' research. In: Proceedings of the International Occupational Hand-Arm Vibration Conference. 1975. Cincinnati: National Institute for Occupational Safety and Health 1977:99-128. (DHEW (NIOSH) Pub No 77-170.)

31 Reynolds DD, Standlee KG, Angevine EN. Hand-arm vibration, Part III: subjective response characteristics of individuals to hand-induced vibration. fournal of Sound and Vibration 1977;51:267-82.

32 Griffin MJ. Hand-transmitted vibration and its effects: coherence between science and standards? In: Proceeding of the Stockholm Workshop 94, Hand-Arm Vibration Syndrome: Diagnostic and Quantitative Relationships to Exposure. May 25-28, 1994. Arbete och Hälsa 1995;5:47-58.

33 Bovenzi M. Italian Study Group on Physical Hazards in the Stone Industry. Hand-arm vibration syndrome and doseresponse relation for vibration-induced white finger among quarry drillers and stonecarvers. Occup Environ Med 1994;51:603-11.

34 Bovenzi M, Franzinelli A, Mancini R, Cannavà MG Maiorano M, Ceccarelli F. Dose-response relation for vascular disorders induced by vibration in the fingers of forestry workers, Occup Environ Med 1995;52:722-30.

35 Bovenzi M, Griffin MJ, Ruffell CM. Acute effects of vibration on digital circulatory function in healthy men. Occup Environ Med 1995;52:834-41.

36 International Organisation for Standardisation. Mechanical vibration and shock-hand-arm vibration-method for the measurement and evaluation of the vibration transmissibility of gloves at the palm of the hand. Geneva: ISO, 1996:10819.

\section{Correspondence and editorials}

Occupational and Environmental Medicine welcomes correspondence relating to any of the material appearing in the journal. Results from preliminary or small scale studies may also be published in the correspondence column if this seems appropriate. Letters should be not more than 500 words in length and contain a minimum of references. Tables and figures should be kept to an absolute minimum. Letters are accepted on the understanding that they may be subject to editorial revision and shortening.

The journal also publishes editorials which are normally specially commissioned. The Editor welcomes suggestions regarding suitable topics; those wishing to submit an editorial, however, should do so only after discussion with the Editor. 